\title{
Puzzle-box learning impairments in young rats with lesions to the "general learning system"
}

\author{
ROBERT THOMPSON, VICTOR M. BJELAJAC, PETER W. HUESTIS, \\ FRANCIS M. CRINELLA, and JEN YU \\ State Developmental Research Institutes, Costa Mesa, California \\ and University of California at Irvine Medical Center, Orange, California
}

\begin{abstract}
Young rats with focal lesions to the general learning system (parietal cortex, dorsal caudatoputamen, globus pallidus, ventrolateral thalamus, substantia nigra, ventral tegmental area, superior colliculus, median raphe, or pontine reticular formation) have previously been reported to be deficient in learning a wide variety of laboratory tasks. The purpose of the current study was to determine whether weanling rats with similarly placed lesions (or frontal cortical or dorsal hippocampal lesions) would subsequently manifest a learning impairment on a series of puzzle-box problems. All groups with lesions to either the subcortical components of the general learning system (GLS) or the frontal (motor) cortex were significantly impaired in overall puzzle-box learning, while the groups with parietal or hippocampal lesions were not. These data suggest that the parietal cortex should be excluded from the GLS of the rat brain.
\end{abstract}

Recent studies have shown that weanling rats sustaining bilateral damage to the region of the parietal cortex, dorsal caudatoputamen, globus pallidus, ventrolateral thalamic nucleus, lateral half of the substantia nigra, ventral tegmental area of Tsai, superior colliculus, median raphe, or pontine reticular formation are deficient in learning a wide variety of laboratory tasks (Thompson, Huestis, Crinella, \& Yu, 1986, 1987). These tasks include detour problems, visual and nonvisual discrimination habits, and a 3-cul maze. By virtue of the general nature of this battery of learning tests (the tests were not limited to one sense modality, to one class of laboratory problems, or to one motivational state), it has been proposed that the foregoing nine brain regions are components of the rat's general learning system (GLS). It has further been proposed that young rats bearing lesions to the GLS can be viewed as being mentally retarded, at least to the extent that one of the distinguishing features of mental retardation is a generalized learning impairment (Clarke \& Clarke, 1973; Denny, 1964; Miller, Hale, \& Stevenson, 1968; Zeaman \& House, 1967).

It is clear that the preceding two proposals require further linkage to data, particularly with respect to the nonspecificity of the learning impairments in young rats with GLS lesions. Choosing a suitable task (or series of tasks) for the purpose of demonstrating nonspecific learning effects is of some concern, since little information is available from the existing literature as to which types of laboratory problems are valid for the study of either animal mental retardation in general or a generalized

We thank Phyllis Wood for typing the manuscript. Address correspondence to R. Thompson, State Developmental Research Institutes, 2501 Harbor Boulevard, Costa Mesa, CA 92626. learning impairment in particular. To date, our laboratory tasks selected for study have been neither too simple (learned after one or two errors) nor too difficult (requiring 50 or more errors to learn) for the young normal albino rat. Since animals with GLS lesions have already been documented to be slower than controls in learning a diversity of problems of intermediate difficulty, it would not be surprising if these animals would also be retarded in learning more difficult problems, such as an 8-arm radial maze task, a delayed alternation habit, or an oddity problem. In like manner, since human mental retardates are apt to be indistinguishable from nonretarded subjects in acquiring certain simple problems (see Zeaman \& House, 1967), our brain-injured rats might also be expected to learn easy problems - taste aversions, oneway active avoidance responses, or simple sensory discrimination habits-about as fast as controls. There does exist, however, a major class of laboratory tasks that are markedly different from those already investigated and that appear on a priori grounds to be suitable to test the pervasiveness of the learning impairment in young rats with lesions to the GLS. The tasks in question involve motor learning and are customarily called latch-box or puzzle-box problems. The feature that these problems have in common pertains to the execution of a manipulative act or series of acts (e.g., the operation of a bolt latch) that is instrumental in the gaining of access to a reward (the opening of a door to a compartment containing food).

Earlier studies on rats have shown that both postoperative acquisition and retention of preoperatively acquired latch-box problems are usually found to be impaired by lesions to the frontal (motor) cortex (Gentile, Green, Niebergs, Schmelzer, \& Stein, 1978; Kolb \& Holmes, 1983; Kolb \& Whishaw, 1983; Lashley, 1935; Spiliotis \& Thompson, 1973; Thompson, Gallardo, \& Yu, 1984a; 
Thompson, Gates, \& Gross, 1979). There is even some evidence that lesions to certain components of the GLS in adult rats may also impair learning (Thompson, Gallardo, \& Yu, 1984b; Thompson, Huestis, \& Yu, 1987) and retention (Spiliotis \& Thompson, 1973; Thompson et al., 1979) of latch-box habits. However, the latter series of experiments investigated performance on only one type of manipulative problem (the operation of latches that required either a lateral or vertical movement of the head or forelimbs), which is hardly sufficient to gauge overall motor-learning skills in an animal capable of making a diversity of manipulative responses. In the current study, a battery of eight separate puzzle-box problems involving the opening of a door leading to a goalbox was devised to assess the capacity for motor learning in GLSlesioned rats. The first four problems were devoid of latches; to gain entrance into the goalbox, the animal was required to slide a door to the left, to slide a door upwards, to pull a door outwards, or to pull a door downwards. Each of the last four problems contained a latch (a butterfly latch attached to the outside of the door, a butterfly latch attached to the inside of the door, a barrelbolt latch, and a hook-and-eye latch) that had to be unlocked to open the door.

Since time is necessarily used as a measure of puzzlebox performance (e.g., time between initial contact with the door or latch and the opening of the door), the motivational level of the subject looms as a critical factor in determining the rate at which these problems are solved. In our laboratory, for example, it is not unusual to observe a water-deprived brain-damaged (or control) rat behave at the very outset as though it is averse to push open a door or operate a latch in order to gain access to a water reward (Spiliotis \& Thompson, 1973; Thompson et al., 1979; Thompson et al., 1984a, 1984b; Thompson, Huestis, \& Yu, 1987). This "reluctance" is not entirely due to timidity brought about by inadequate adaptation to the apparatus, since the same animal will unhesitatingly run from the choice chamber to the goalbox and drink the water, provided that the door is left ajar. In view of the possibility that a deficit in puzzle-box learning can be secondary to a motivational involvement, it was imperative to obtain an objective measure of motivation in our brain-damaged and control rats. The measure that was employed in the current study consisted of time elapsing from the moment the startbox door was raised to the moment the rat touched any part of the doorframe, door, or latch.

Another important procedural decision that had to be made dealt with either giving a fixed number of trials on each puzzle-box problem or training the rat on each problem to an arbitrary criterion of learning. The former procedure was adopted for three main reasons. First, limiting the number of trials per problem would result in shortening the duration of the experiment. This consideration was important to the extent that rats with lesions to certain components of the GLS (e.g., globus pallidus, substantia nigra, and pontine reticular formation) are not apt to survive prolonged periods of water or food deprivation. Second, providing a limited number of trials per problem reduces the possibility that any learning impairment displayed by the brain-injured animals is attributable to differential susceptibility to negative transfer effects manifested, for example, in perseverative responding (repeating a response that was correct on a preceding problem). Third, there is some evidence from studies of retarded (Baumeister, Hawkins, \& Holland, 1966; Kahn \& Burdett, 1967; Simenson, 1973) and nonretarded (Ackerman, 1987) human subjects that cognitive factors may play a greater role during the early stages of motor learning than during the later stages.

Specifically, weanling rats subjected to either sham operations or bilateral lesions to one of the nine components of the GLS were rested for 3 weeks and subsequently given 10 trials on each problem composing the motorlearning test battery. For comparative purposes, two additional groups of brain-damaged rats were examined. The first consisted of animals with small bilateral lesions to the frontal (motor) cortex. This group was included primarily for the purpose of validating the assumption that the test battery was indeed measuring some aspect of motor-skill learning that depended upon the integrity of cortical motor mechanisms. The second group consisted of animals with multiple bilateral electrolytic lesions to the dorsal hippocampus. Since the results of a pilot study suggested that hippocampal lesions have little effect on acquisition of puzzle-box tasks, this group was chosen to serve the purpose of demonstrating some degree of neuroanatomical localization of motor learning in the white rat. Another reason for including this group within the current study was to provide further documentation that the hippocampus, despite being widely accepted as a key brain structure intervening in the formation of learned habits, fails to qualify as a component of the rodent's GLS.

\section{METHOD}

\section{Subjects and Surgery}

Weanling (22-25-day-old) male Sprague-Dawley albino rats $(55-65 \mathrm{~g})$ were prepared for surgery under deep chloral hydrate anesthesia $(400 \mathrm{mg} / \mathrm{kg})$. The lesions in nine experimental groups were accomplished electrolytically by passing a constant anodal current of 1.0-2.0 mA for a duration of 5-10 sec through an implanted stainless steel electrode $(.5 \mathrm{~mm}$ in diameter) with $.5-1.0 \mathrm{~mm}$ of the tip exposed. One of these groups (Group DCP) suffered multiple bilateral lesions to the dorsal caudatoputamen (with the head of the rat oriented horizontally in the stereotaxic headholder, the coordinates were $7.5 \mathrm{~mm}$ anterior to lambda, 2.0 and $3.0 \mathrm{~mm}$ lateral to the longitudinal sinus, and $4.5 \mathrm{~mm}$ ventral from the surface of the brain). The other eight experimental groups received lesions to the globus pallidus (Group GP: $7.0 \mathrm{~mm}$ anterior, $2.7 \mathrm{~mm}$ lateral, and $6.0 \mathrm{~mm}$ ventral), ventrolateral thalamus (Group VLT: $5.2 \mathrm{~mm}$ anterior, $1.9 \mathrm{~mm}$ lateral, and $6.0 \mathrm{~mm}$ ventral), substantia nigra (Group SN: $2.9 \mathrm{~mm}$ anterior, $2.2 \mathrm{~mm}$ lateral, and $7.0 \mathrm{~mm}$ ventral), ventral tegmental area (Group VTA: $2.5 \mathrm{~mm}$ anterior, $.8 \mathrm{~mm}$ lateral, and $7.5 \mathrm{~mm}$ ventral), superior colliculus (Group SC: $1.7 \mathrm{~mm}$ anterior, 1.0 and $2.0 \mathrm{~mm}$ lateral, and $4.2 \mathrm{~mm}$ ventral), median raphe (Group MR: $.7 \mathrm{~mm}$ anterior, $0 \mathrm{~mm}$ lateral, and $7.5 \mathrm{~mm}$ ventral), pontine reticular formation (Group PRF: .9 mm anterior, $1.0 \mathrm{~mm}$ lateral, and $7.0 \mathrm{~mm}$ ventral), or dorsal hippocampus (Group DH: $4.9 \mathrm{~mm}$ anterior, $1.0,2.0$, and $3.0 \mathrm{~mm}$ lateral, and $3.5 \mathrm{~mm}$ ventral). Two additional experimental groups 
were subjected to bilateral lesions to the parietal cortex (Group PC) and frontal cortex (Group FC) by means of the suction method. The last group (Group C) served as operated controls, undergoing the same surgical procedure as the experimental groups, save for drilling of the skull and lesioning of the brain.

Throughout the recovery period, the animals were usually housed, 2 or 3 per cage, in medium-sized hanging wire cages containing a constant supply of food pellets and water. During the 1st postoperative week, a dish of sweetened wet mash was placed daily in each cage to encourage early resumption of food intake. During the 3rd postoperative week, all the animals were handled daily for approximately $5 \mathrm{~min}$. During this handling period and the subsequent period of behavioral testing, the experimenters were given no knowledge as to the group to which each subject belonged. The animals were maintained on a 12:12-h light:dark cycle with lights on at 0600 , and they were trained only during the light phase.

\section{Apparatus}

The puzzle-box apparatus was largely made of plywood and consisted of a startbox $(18.5 \times 22.5 \times 30.5 \mathrm{~cm})$ painted flat white, choice chamber $(21.3 \times 22.5 \times 30.5 \mathrm{~cm})$ painted flat white, and a goalbox $(30.5 \times 38.5 \times 30.5 \mathrm{~cm})$ painted flat black. A clear Lexan guillotine door separated the startbox from the choice chamber. Interchangeable smoked Lexan partitions, each containing a Lexan door, could be interposed between the choice chamber and goalbox. During preliminary training, a partition containing a "conventional" door that could be pushed open was used. Partitions containing doors that were employed during experimental training are shown in Figure 1. The entire apparatus was covered by a Plexiglas lid and illuminated by conventional fluorescent ceiling lighting.

Problems 1-4 contained doors with no latches. Specifically, Problem 1 consisted of a door (with a 1.3-cm diameter hole drilled through its center) that had to be slid to the left in order to gain access to the goal box. Problem 2 contained a door (with a similarly drilled hole through its center) that had to be pushed upwards. A counterweight was attached to the vertically sliding door to prevent it from lowering once it had been raised. Problem 3 contained a door with a vertically mounted metal bar acting as a handle. Opening the door required pulling the handle outward. Problem 4 contained a door (with a drilled hole in its center) that had to be pulled outward and then downward. A counterweight was attached to the door to prevent it from falling sharply to the floor once it had been partially pulled downward.

Problems 5-8 contained doors that could be pushed open only after a latch was unlocked. Specifically, Problem 5 consisted of a butterfly latch (mounted on the choice-chamber side) that had to be rotated in a clockwise direction to the vertical position in order to unlock the door. Problem 6 contained a butterfly latch that was attached on the goalbox side; the latch had to be rotated in clockwise fashion to the vertical position in order to unlock the door. Problem 7 consisted of a barrel-bolt latch that had to be slid to the right at least $8 \mathrm{~cm}$ in order to unlock the door. Finally, Problem 8 consisted of a hook that had to be elevated at least $.8 \mathrm{~cm}$ in order to unlock the door.

The majority of animals opened the doors in the following ways: inserting the nose in the hole and pushing to the left (Problem 1); inserting the nose in the hole and pushing upwards (Problem 2); grabbing the handle with the teeth and pulling outwards (Problem 3); placing the paws on the upper edge of the door and pulling downwards (Problem 4); rotating the latch with the nose (Problem 5); rotating the latch with the paws (Problem 6); pushing the barrel bolt to the right with the nose (Problem 7); and elevating the hook with the nose (Problem 8).

\section{Procedure}

Preliminary training. Following a 3-week recovery period, the animals were weighed and then deprived of water in their home cages. After 2 days of deprivation, each animal was allowed to ex-
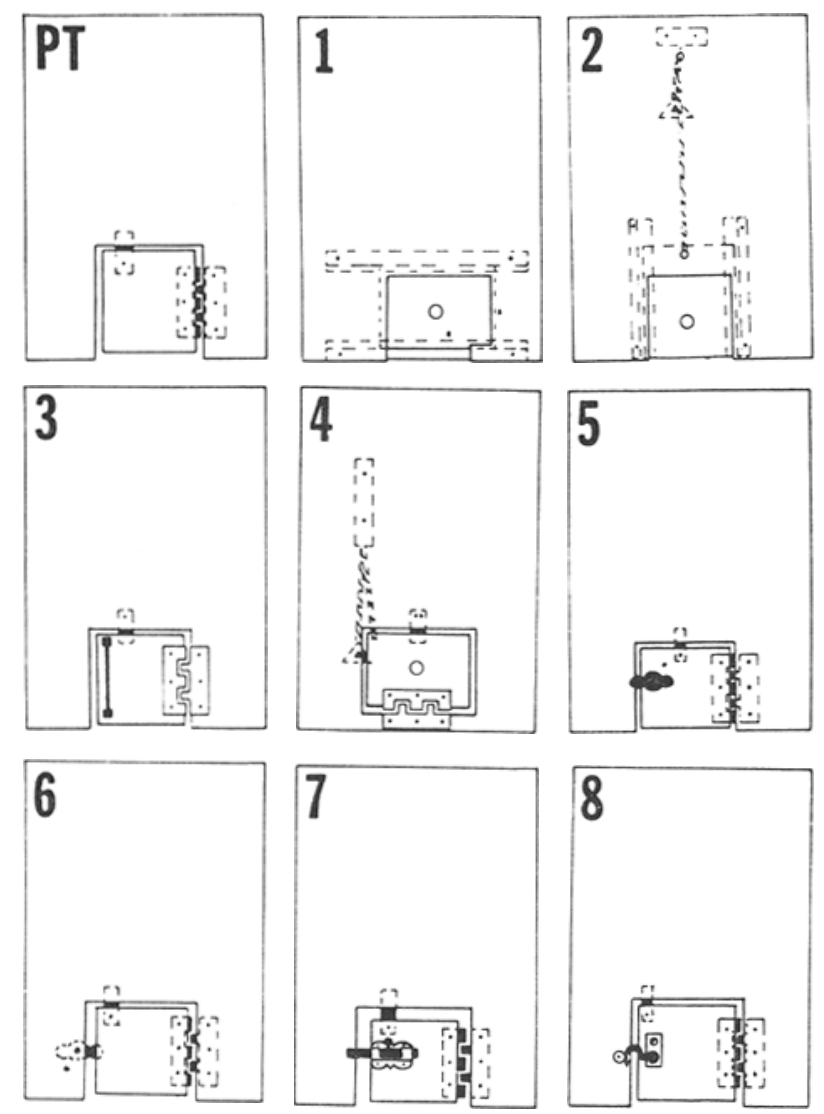

Figure 1. Front view of the interchangeable partitions containing doors, showing the door used in preliminary training (PT) and the eight puzzle-box problems.

plore the entire apparatus for $10 \mathrm{~min}$ (Day 1, Monday). During this phase of training, the startbox door was in the raised position and the door separating the choice chamber from the goalbox was left ajar. A dish of water and a dish of sweetened wet mash were available in the goalbox, where the animals could freely ingest. To facilitate familiarity with the apparatus, the animals were frequently returned to the startbox once they ingested the water or mash for a few seconds.

On Day 2 (Tuesday), the animals-usually run in squads of 2 or 3 -were required to push open the door between the choice chamber and goalbox in order to gain access to the water and mash. Ten trials were given, with intertrial intervals of 30-60 sec. Each trial was initiated with the placing of the rat in the startbox and the raising of the startbox door; it was terminated when the rat ran through the choice chamber, pushed open the door, entered the goalbox, and ingested the water or mash for $5 \mathrm{sec}$. The rat was then transferred to a holding cage to await the next trial. Most of the animals were permitted to ingest the water and mash for approximately $120 \mathrm{sec}$ on the 10th trial. This period, however, was reduced by at least $50 \%$ for the animals that were consistently reluctant to leave the startbox, slow in traversing the choice chamber, or hesitant in displacing the door or in ingesting the water or mash.

Throughout the experiment, two time scores were recorded on each trial. The first was accomplished by means of an electric timer, which was activated when the startbox door was raised and deactivated when the startbox door was lowered, the latter occurring at the moment the rat touched any part of the partition, door, or latch. The second was accomplished by a hand-held stopwatch, which was started when the startbox door was lowered and stopped when the animal entered the goalbox. 
Administering the test battery. Problem 1 was given on Day 3 (Wednesday), Problem 2 on Day 4 (Thursday), and Problem 3 on Day 5 (Friday). At the completion of testing on Day 5, the animals were given continuous access to water in their home cages until Day 6 (Saturday). The remaining five problems were then administered on Days 8-12 (Problem 4 on Monday, Problem 5 on Tuesday, etc.).

Ten trials were given on each problem, with intertrial intervals of 40-200 sec. A trial commenced when the startbox door was raised and usually concluded when the animal successfully opened the door, entered the goalbox, and ingested the water or mash for $5 \mathrm{sec}$. The animal was then removed from the goalbox and returned to the holding cage to await the next trial. In the event the animal failed to open the door within $60 \mathrm{sec}$, the door was partially opened by the experimenter, allowing a space for the rat to enter the goalbox.

In an effort to provide some objective measure of motivation, the time elapsing from the moment the startbox door was raised to the moment the rat made contact with any part of the partition, door, or latch was recorded (to the nearest second) on every trial.

Problems 1,4 , and 7 were found to be relatively difficult to solve for the control animals, and as a consequence, a correct response was defined as the opening of the door and the entering of the goalbox (with all four feet within the threshold) within $60 \mathrm{sec}$ after initial contact was made with any part of the partition, door, or latch. For the remaining five problems, a correct response was recorded when an interval not exceeding $5 \mathrm{sec}$ occurred between initial contact with the partition, door, or latch and entrance into the goalbox.

\section{Histology}

At the conclusion of postoperative testing, each brain-damaged rat was killed with an overdose of chloral hydrate, its vascular system perfused with $10 \%$ formalin, and the brain removed and stored in $10 \%$ formalin for $2-4$ days. Before sectioning, the cortical lesions were reconstructed on Lashley-type brain diagrams, from which the percentage of neocortical destruction was estimated in a manner similar to that described by Lashley (1929). Subsequently, each brain was blocked, frozen, and sectioned at $90 \mu$. Every third section through the lesion was retained and later photographed at $12 \times$, using the section as a negative film in an enlarger.

\section{Measures of Performance}

Two measures of puzzle-box learning were considered: the number of errors committed on each problem, and the total errors committed on the battery of eight problems. Since the individual problems were not of uniform difficulty for the control rats, the latter measure would appear to provide the best assessment of overall motor-learning capacity in the various brain-damaged groups.

In like manner, the best estimate of the overall level of motivation operating within a given subject was deemed to be the sum of the mean response latency scores across the battery of eight tests.

All intergroup differences in performance measures (particularly those between each brain-damaged group and the controls) were evaluated by the Mann-Whitney $U$-test (two-tailed), provided that the Kruskal-Wallis one-way analysis of variance yielded an $H$ that was significant at least at the .05 level.

\section{RESULTS}

\section{Mortality Rate and Discarded Subjects}

Of the original 178 weanling male rats undergoing surgery, 21 died prior to the onset of preliminary training, and 4 died during the course of behavioral testing. The highest mortality rate occurred in Groups SC, VTA, and PRF. An additional 36 animals were excluded from the experiment, because their lesions were found to be too small, grossly asymmetrical, or distant from the intended target area. All of the remaining 117 brain-damaged and control animals appeared healthy and alert by the end of the 3 rd postoperative week.

\section{Histology}

The lesions sustained by the rats in Group PC (the estimated extent of neocortical damage averaged $19.7 \%$, with a range of $16 \%-24 \%$ ) were generally concentrated in Areas 1 and 2 of the parietal cortex, according to the atlas of Zilles (1985). On the other hand, the lesions sustained by Group FC (the estimated extent of damage averaged $10.3 \%$, with a range of $8 \%-14 \%$ ) were largely localized to Zilles' Areas 1, 2, and 3 of the frontal cortex. Figures 2 and 3 show representative cortical lesions in these two groups.

The subcortical lesions suffered by the various groups of the current experiment were roughly similar in topography and magnitude to those sustained by the corresponding groups investigated in earlier studies of the neuroanatomy of mental retardation in the rat (Thompson, Huestis, et al., 1986; Thompson, Huestis, et al., 1987). Typical lesion placements in these groups are shown in Figures 4-12.

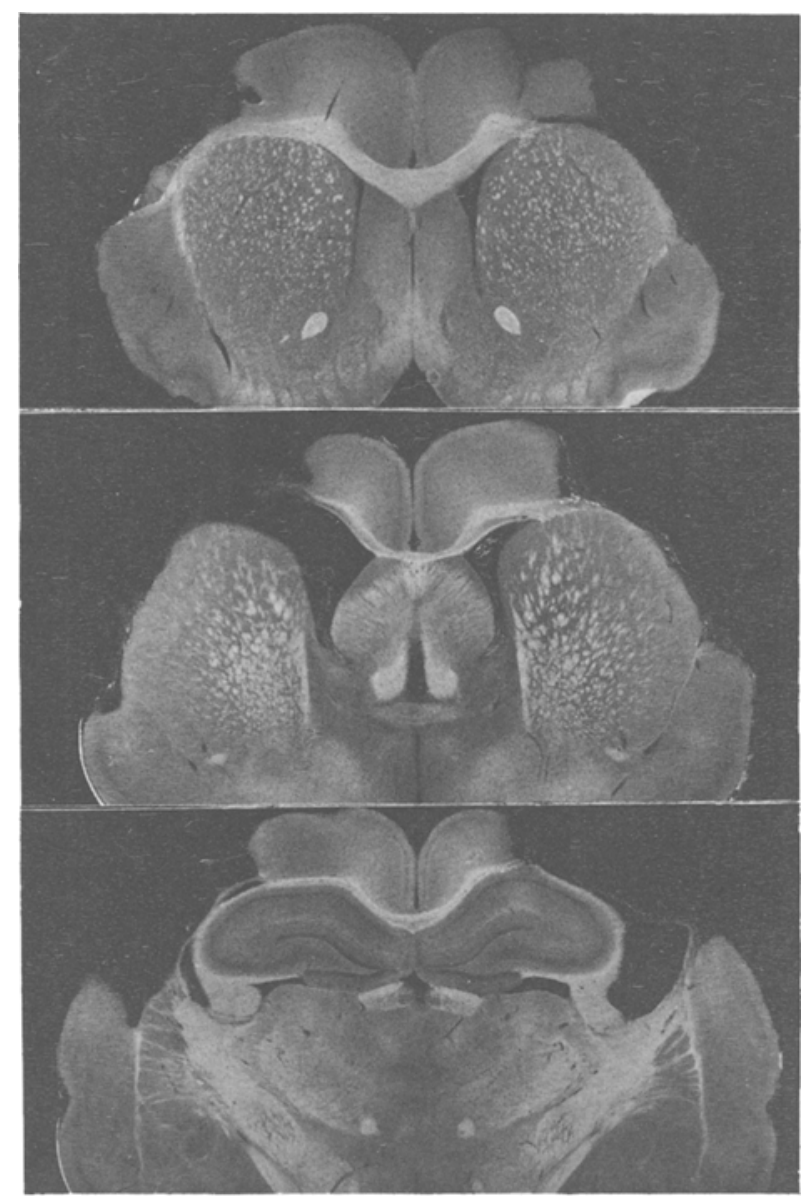

Figure 2. Unstained sections showing a lesion to the parietal cortex. 


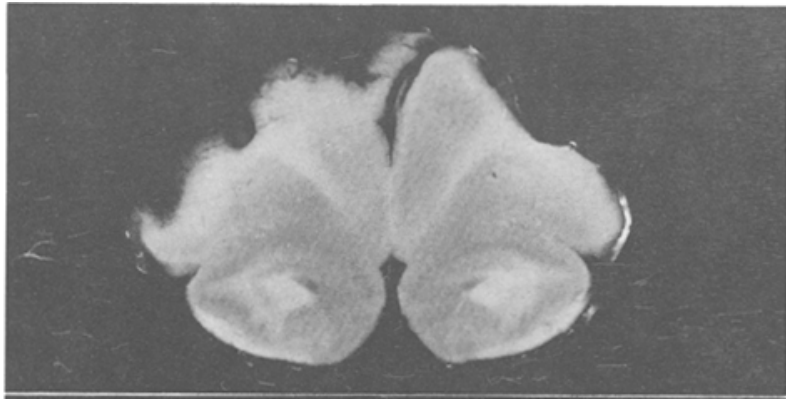

$d f=11, p s<.05$ ) and that they also differed significantly in terms of total errors committed on the test battery $(H=30.9, d f=11, p<.01)$. Comparisons between each brain-injured group and the controls revealed that Group GP exhibited the greatest loss in puzzle-box learning (impaired on six problems), followed in descending order by Groups VTA (impaired on five problems), FC (impaired on four problems), DCP, SN, SC, PRF (impaired on three problems), VLT, MR, (impaired on two problems), DH (impaired on one problem), and, finally, PC (unimpaired on all problems).

With respect to total error scores, all groups with lesions in the various components of the GLS were significantly inferior to the controls, save for Group PC. Group FC was also significantly deficient in puzzle-box learning, but Group DH was not.

Response latency scores. These scores (time elapsing between the raising of the startbox door and contact with any part of the interchangeable partition, door, or latch), which were intended to serve as a measure of motivation, are also presented in Table 1. Separate analyses of variance disclosed that the groups were significantly different on every one of the eight problems $(H \mathrm{~s}>28$,

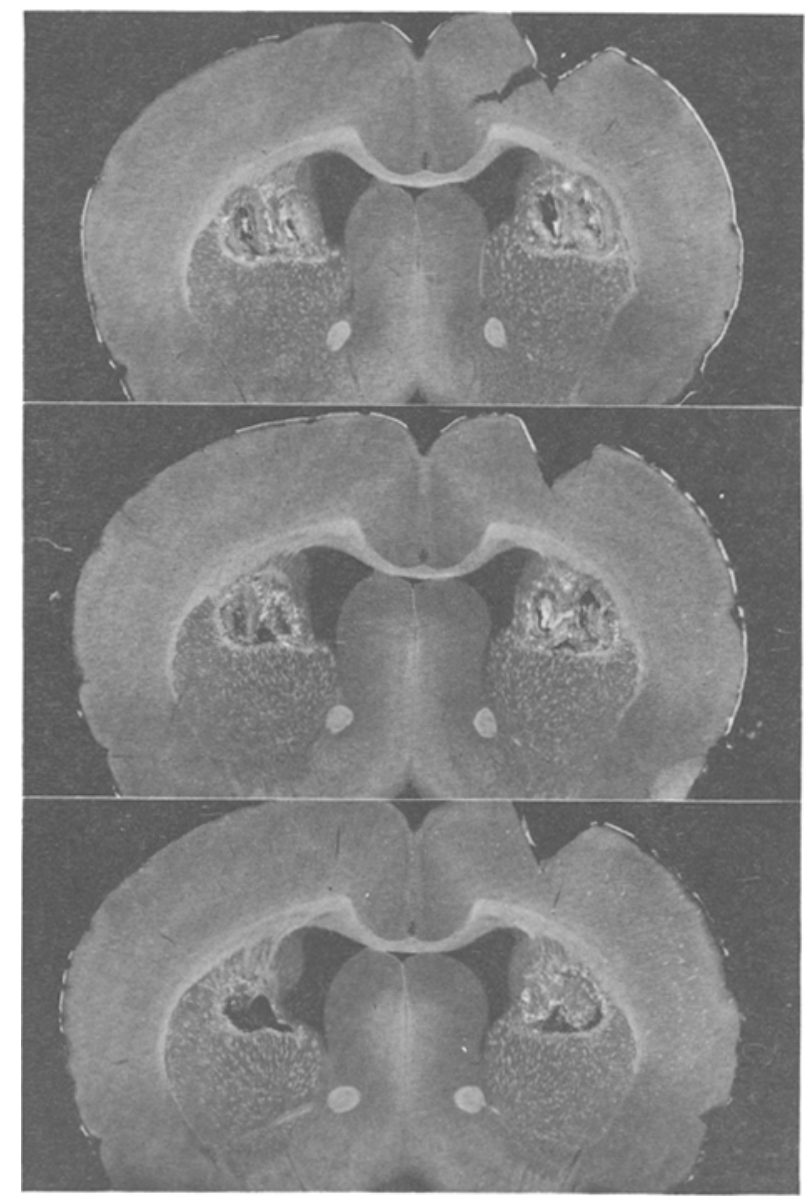

\section{Body Weight}

After a 3-week recovery period, the mean (and ranges of) body weights in grams were $159(128-219)$ for Group C, 150 (95-190) for Group PC, 150 (134-202) for Group FC, 148 (110-191) for Group DCP, 128 (103-160) for Group GP, 158 (127-190) for Group VLT, 151 (129-176) for Group SN, 154 (134-175) for Group VTA, 148 (119-176) for Group SC, 138 (123-151) for Group MR, 167 (141-186) for Group PRF, and $186(142-227)$ for Group DH. The Kruskall-Wallis one-way analysis of variance applied to these data yielded an $H$ of $28.4(d f=11, p<.01)$. Specific comparisons by the Mann-Whitney $U$-test disclosed that Groups GP and MR were significantly lighter than the controls, while Group DH was significantly heavier than the controls $(p s<.01)$.

\section{Puzzle-Box Performance}

Error scores. Table 1 presents the mean error scores on each problem as well as the total errors committed on all eight problems, for the various groups. Separate analyses of variance disclosed that the groups differed significantly on Problems 2, 4, 5, 6, 7, and $8(H \mathrm{~s}>23$,

Figure 4. Unstained sections showing a lesion to the dorsal caudatoputamen. 


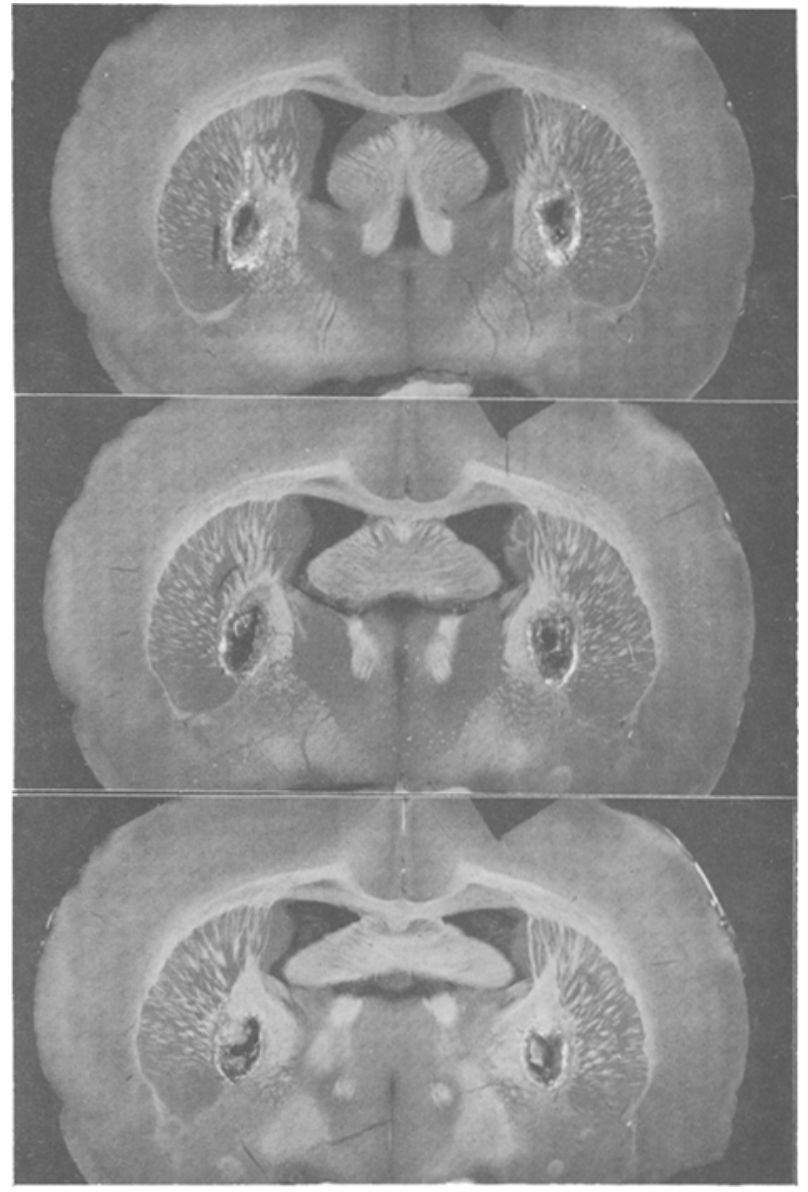

Figure 5. Unstained sections showing a lesion to the globus pallidus.

$d f=11, p s<.01)$. Comparisons between each braindamaged group and the controls showed that Group FC on three problems and Group SN on all eight problems exhibited significantly longer latency scores than did the controls. Interestingly, Groups MR and DH exhibited significantly shorter latency scores than the controls on four and seven problems, respectively.

With respect to total latency scores, only Group SN was significantly slower than the controls in overall responsiveness to the doors. Groups MR and DH, on the other hand, were significantly faster than the controls in this regard.

\section{DISCUSSION}

\section{General Findings}

By and large, the findings of the current experiment accord with earlier observations on the effects of focal brain lesions on the performance of puzzle-box (latch-box) tasks. Correspondences have been observed with respect to acquisition (or retention) deficits following lesions to the frontal cortex (Gentile et al., 1978; Kolb \& Holmes, 1983; Kolb and Whishaw, 1983; Thompson et al., 1979, 1984a), caudatoputamen (Spiliotis \& Thompson, 1973), globus pallidus (Thompson, Huestis, \& Yu, 1987), ventrolateral thalamus (Thompson et al., 1979, 1984b), substantia nigra (Spiliotis \& Thompson, 1973; Thompson, Huestis, \& Yu, 1987), ventral tegmental area (Spiliotis \& Thompson, 1973), median raphe (Thompson et al., 1979; Thompson, Huestis, \& Yu, 1987), or pontine reticular formation (Spiliotis \& Thompson, 1973; Thompson, Huestis, \& Yu, 1987). Similarly, there is agreement concerning the absence of acquisition or retention deficits following lesions restricted to either the parietal cortex (Gentile et al., 1978; Kolb \& Walkey, 1987; Kolb \& Whishaw, 1983; Thompson et al., 1984a) or hippocampus (Thompson et al., 1979).

One possible inconsistency concerns the appearance of a puzzle-box deficit arising from lesions to the superior colliculus. In an earlier study with adult rats as subjects (Spiliotis \& Thompson, 1973), damage to this midbrain structure did not adversely affect retention of latch-box tasks involving the manipulation of butterfly, bolt, or hook-and-eye latches. This discrepancy could have emerged from diminutive destruction of the superior col-

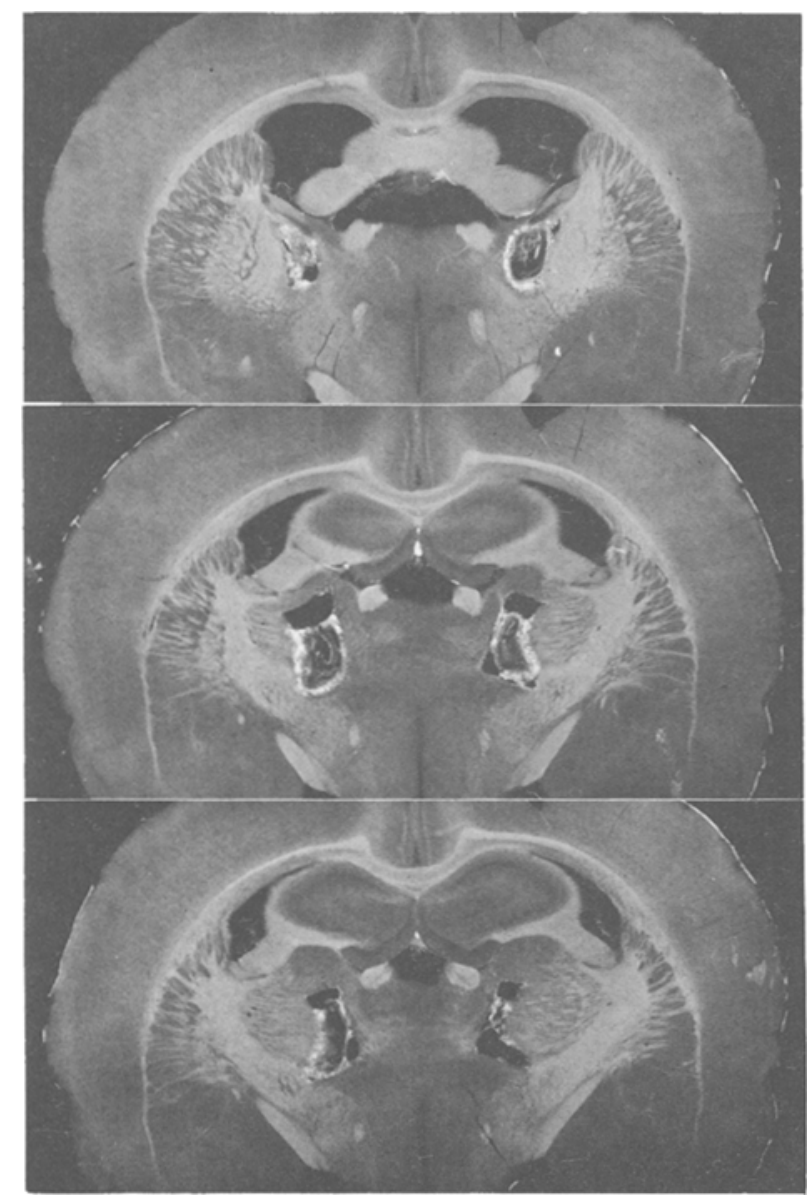

Figure 6. Unstained sections showing a lesion to the region of the ventrolateral thalamus. 


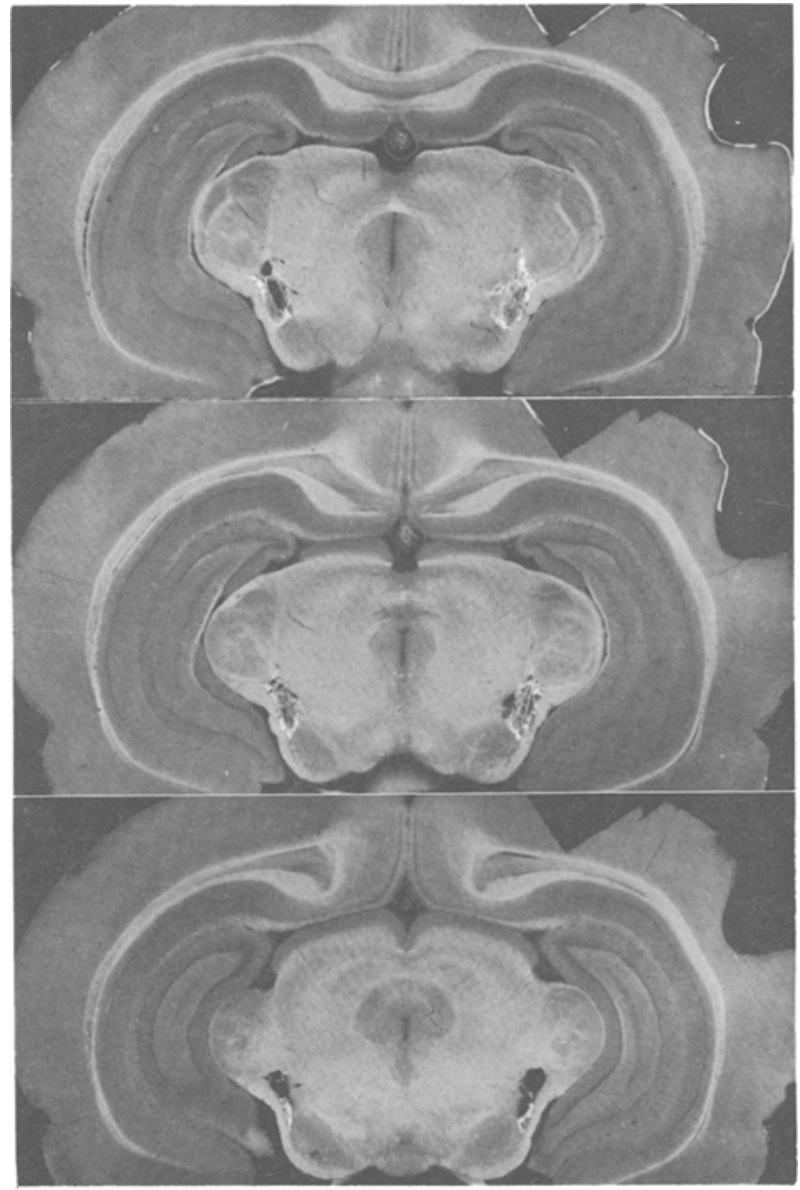

Figure 7. Unstained sections showing a lesion to the substantia nigra.

liculus in the earlier study, from the investigation of adult rather than young rats, or from an examination of retention as opposed to acquisition of manipulative problems. However, emphasis should be placed on the latter variable since there is some evidence that acquisition of laboratory tasks is more vulnerable to disruption by collicular lesions than the performance of tasks already acquired (Berlucchi, Sprague, Levy, \& DeBerardino, 1972, Thompson, Huestis, et al., 1987).

\section{The General Learning System}

Anatomical considerations. As mentioned at the outset of this paper, if the parietal cortex, dorsal caudatoputamen, globus pallidus, ventrolateral thalamus, substantia nigra, ventral tegmental area, superior colliculus, median raphe, or pontine reticular formation are indeed components of the rat's GLS, then it would be expected that selective damage to these structures would significantly compromise skilled (manipulative) movement learning. It is important to note that the battery of tasks devised to test this prediction demanded an assortment of response patterns to solve the various problems. It is equally important to note that small lesions of the frontal cortex were found to impair overall performance on this battery, suggesting that the chosen tasks invoked the operation of cortical motor mechanisms.

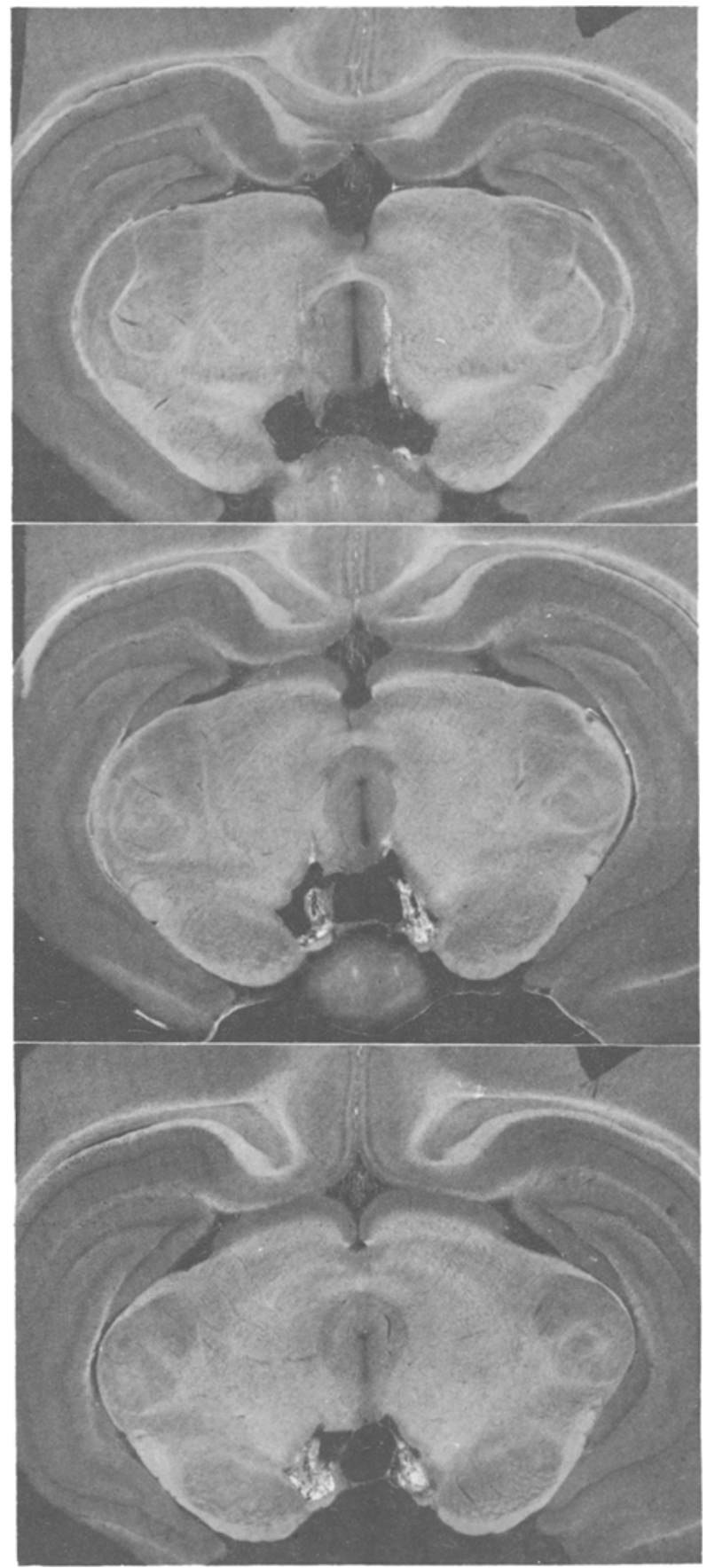

Figure 8. Unstained sections showing a lesion to the ventral tegmental area of Tsai. 


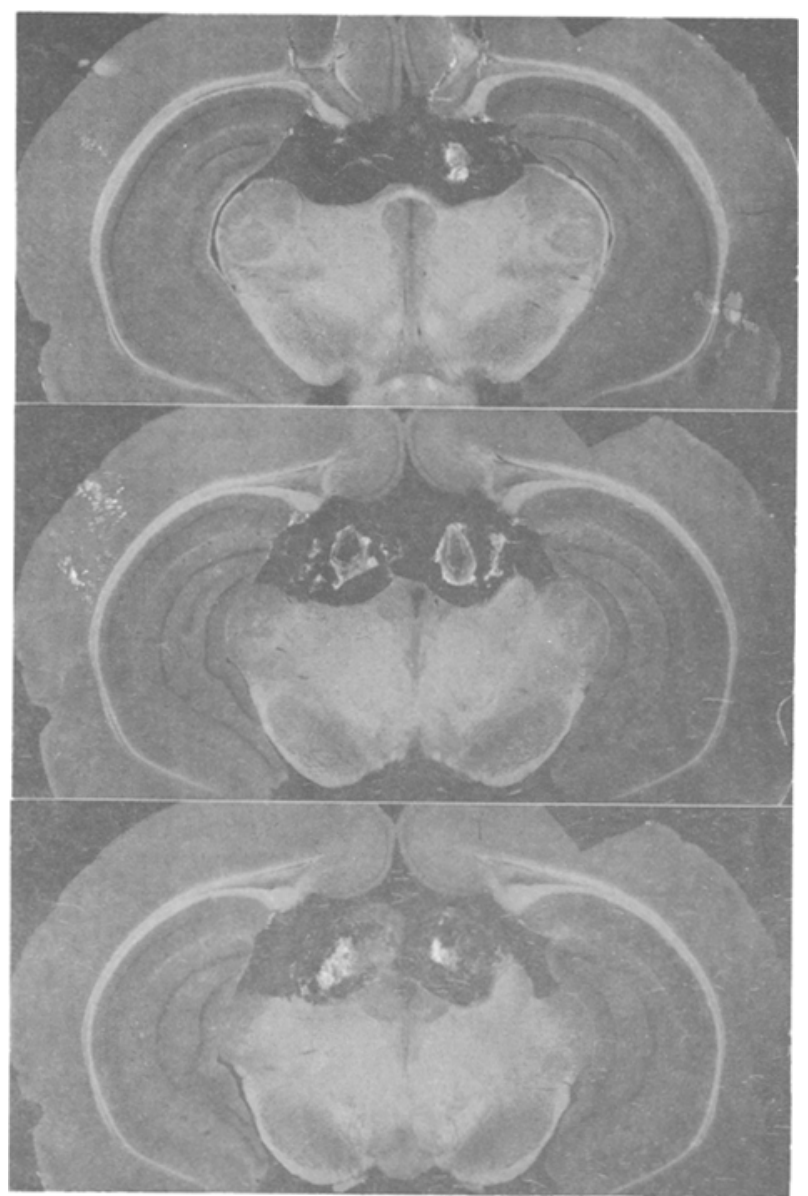

Figure 9. Unstained sections showing a lesion to the superior colliculus.

The results of this test are unequivocal with respect to the structures that are to be retained within the GLS. While lesions to any one of the eight subcortical components of the GLS impaired overall motor learning ability, lesions to the only cortical component of the GLS (parietal cortex) did not. Since earlier studies have also failed to document deficits in puzzle-box learning in rats with parietal lesions, (Kolb \& Walkey, 1987; Thompson et al., 1984a), it seems warranted to eliminate this cortical structure from the GLS of the rat brain. Parenthetically, the nonappearance of an overall motor learning deficit in Group DH further justifies the omission of the hippocampus from the rodent's GLS.

Perhaps the most disquieting feature about the current makeup of the GLS is that it fails to contain any part of the cerebral cortex or hippocampal formation, the two brain regions most frequently cited in connection with mammalian learning and memory. Obviously, the exclusion of these (or any other) brain structures from the GLS does not imply that they are devoid of any significant role in learning. Rather it suggests that neocortical and hip- pocampal regions are not critical for acquisition of a broad spectrum of laboratory tasks. In other words, these telencephalic structures have specific functions in learning, which are to be contrasted with the seemingly nonspecific functions served by the various components of the GLS. As mentioned earlier (Thompson \& Yu, 1987), the key to the unravelling of the neuroanatomy of learning may lie in the identification of those pathways functionally linking neocortical and hippocampal structures with the GLS.

On the other hand, one of the more intriguing features of the GLS is that most of its components are cited in discourses about the neural circuitry of the basal ganglia and related nuclei (see Thompson, Huestis, et al., 1987). For example, six of the eight specific regions currently included within the GLS (caudatoputamen, globus pallidus, ventrolateral thalamus, substantia nigra, ventral tegmental area, and superior colliculus) are shown in Heimer, Alheid, and Zaborszky's (1985) summary diagrams of the synaptic relations between the basal ganglia and other brain areas. On the strength of this degree of overlap, the basal ganglia and anatomically related structures are conceived as constituting the core of the rodent's GLS. This

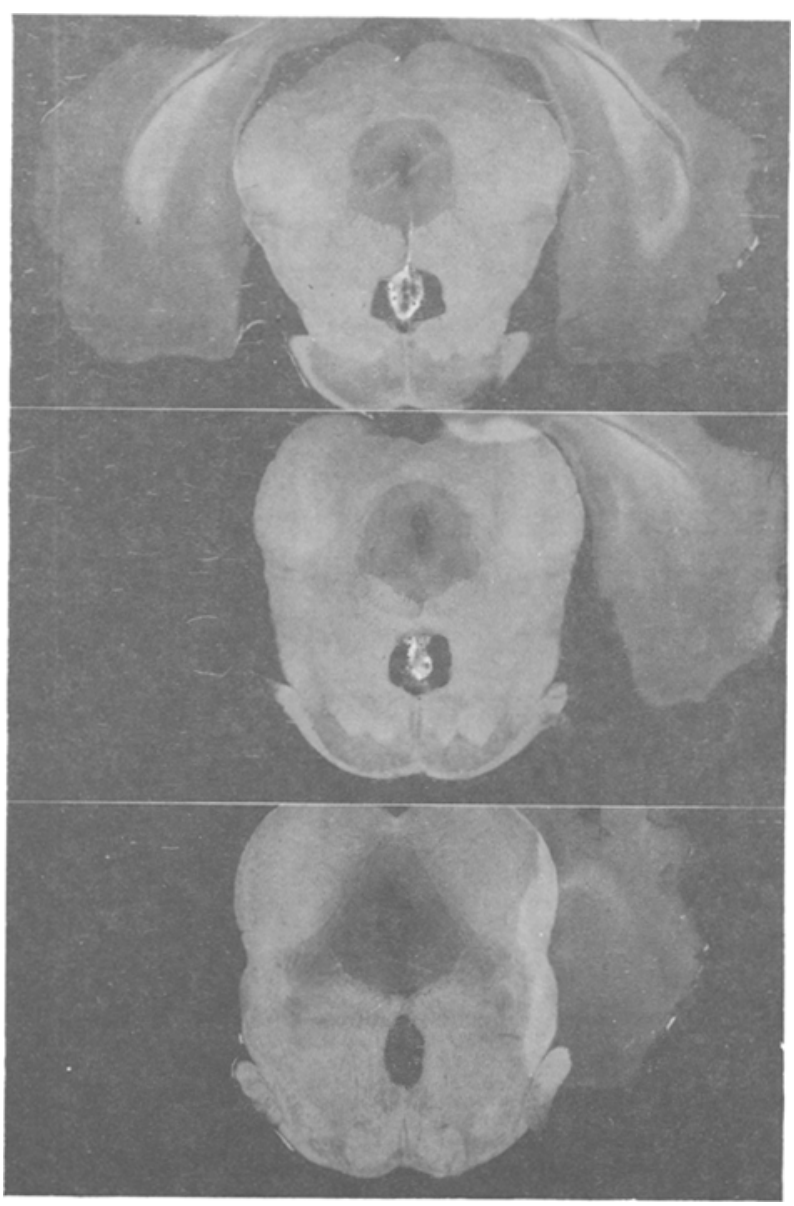

Figure 10. Unstained sections showing a lesion to the median raphe. 


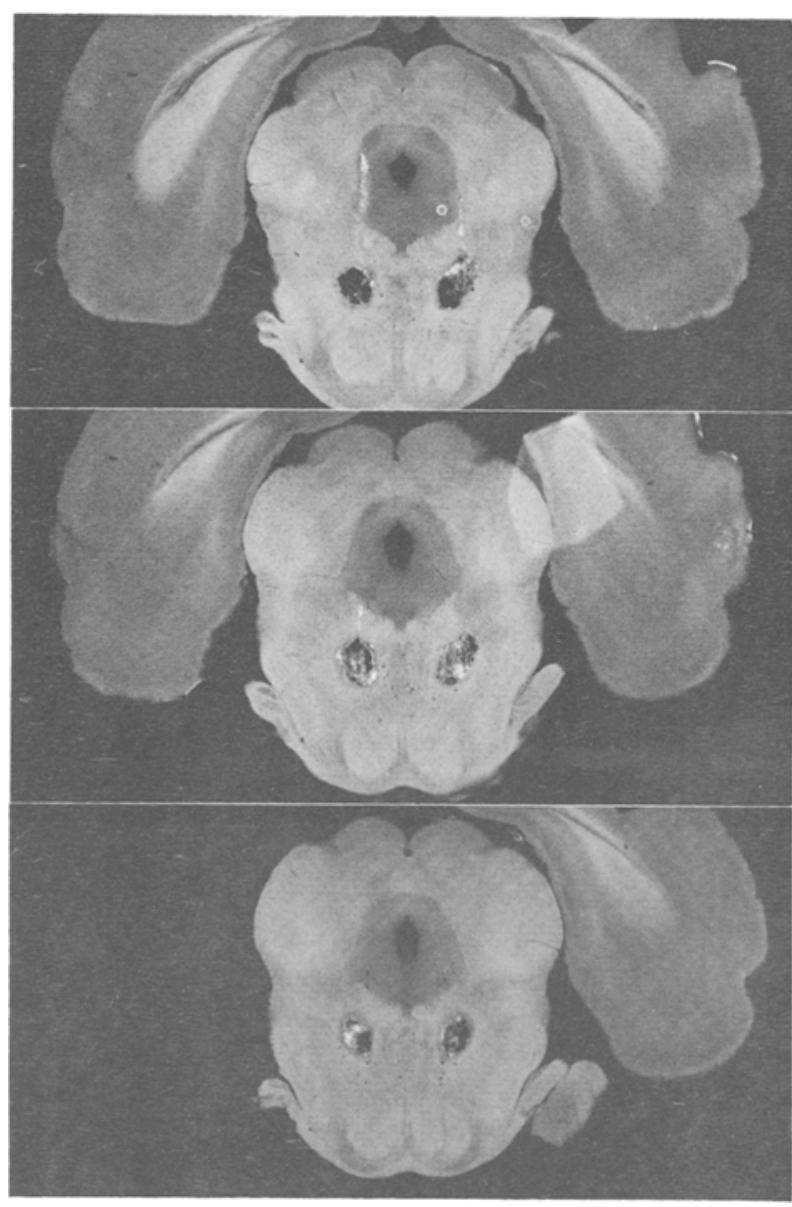

Figure 11. Unstained sections showing a lesion to the pontine reticular formation.

view is admittedly open to question to the extent that lesions to certain brain regions composing (or intimately associated with) the basal ganglia (e.g., entopeduncular nucleus, subthalamic nucleus, and ventromedial thalamic nucleus) have not been found to produce a generalized learning impairment in young rats (Thompson, Huestis, et al., 1986, 1987). However, these negative findings could reflect either the existence of a specialized subset of basal gangliar nuclei fundamental for general learning ability or the parallel participation of several nuclei within the circuits of this anatomical system.

Before this section concludes, it should be noted that our use of the electrolytic method to induce subcortical brain damage (which destroys both cell bodies and fibers of passage at the site of the lesion) tends to hinder efforts to proceed with a deeper analysis of the anatomofunctional relationships that might exist among the structures of the GLS. According to one study, damage to both neurons and fibers of passage within a given component of the GLS may be necessary to elicit significant learning deficits on a variety of laboratory problems (Thompson, Gibbs, Ris- tic, Cotman, \& Yu, 1986). If these findings are confirmed, tracing functional links within the anatomical circuits of the GLS will be quite laborious and convoluted.

Functional considerations. While the results bearing on the anatomical composition of the GLS seem relatively straightforward, they provide little in the way of direct clues concerning either the cognitive nature of the general learning impairment or the physiological basis of the specific motor-learning impairment. For example, it cannot be determined whether the broad learning impairment arising from lesions to the GLS is a manifestation of a sensorimotor (or some other noncognitive) disorder or whether it is a product of (or exacerbated by) a coexisting cognitive disorder. Similarly, it is unclear whether a common dysfunction underlies the motor-learning impairment in the various groups with GLS lesions, or whether the dysfunction responsible for the impairment in some groups is different from that in other groups. In light of the response latency data, however, a motivational involvement does not appear to lie at the basis of the

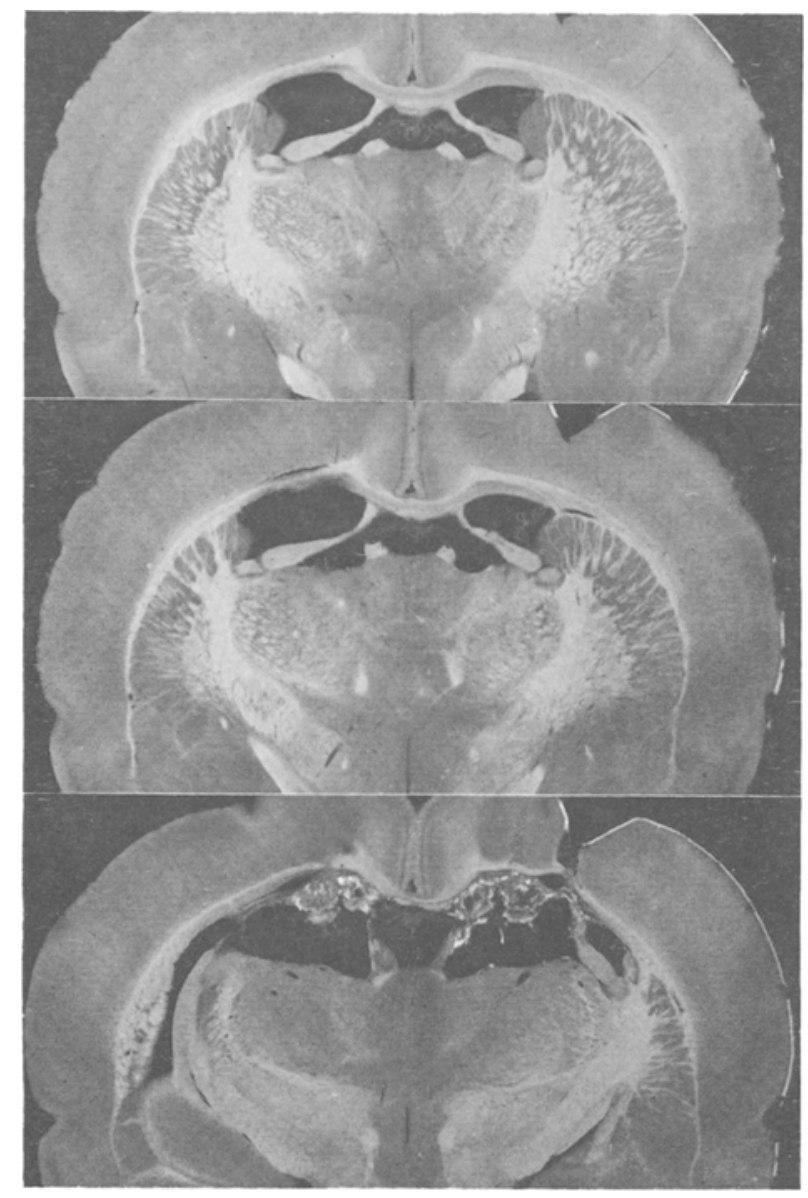

Figure 12. Unstained sections showing a lesion to the dorsal hippocampus. 
Table 1

Mean Errors and Mean Response Latencies (in Seconds) on Each Problem for All Groups

\begin{tabular}{|c|c|c|c|c|c|c|c|c|c|c|c|c|c|}
\hline \multirow[b]{2}{*}{ Problem } & \multirow[b]{2}{*}{ Score } & \multicolumn{12}{|c|}{ Group } \\
\hline & & $\begin{array}{c}C \\
(20)\end{array}$ & $\begin{array}{c}P C \\
(12)\end{array}$ & $\begin{array}{c}\text { DCP } \\
\text { (8) }\end{array}$ & $\begin{array}{l}\text { GP } \\
(8)\end{array}$ & $\begin{array}{l}\text { VLT } \\
\text { (7) }\end{array}$ & $\begin{array}{l}\text { SN } \\
(8)\end{array}$ & $\begin{array}{l}\text { VTA } \\
\text { (11) }\end{array}$ & $\begin{array}{l}\text { SC } \\
\text { (9) }\end{array}$ & $\begin{array}{c}\text { MR } \\
\text { (9) }\end{array}$ & $\begin{array}{c}\text { PRF } \\
\text { (6) }\end{array}$ & $\begin{array}{c}\text { FC } \\
(10)\end{array}$ & $\begin{array}{c}\mathrm{DH} \\
(9)\end{array}$ \\
\hline \multirow[t]{2}{*}{1} & Errors & 6.0 & 7.5 & $9.9 \dagger$ & $8.8^{*}$ & 8.3 & 6.8 & 8.5 & 8.1 & 7.0 & 8.8 & $8.7^{*}$ & 6.1 \\
\hline & Time & 5.3 & 6.0 & 3.9 & 7.0 & 3.7 & $26.0 \dagger$ & 5.1 & 5.2 & $2.4^{*}$ & 5.0 & 6.7 & $2.8^{*}$ \\
\hline \multirow[t]{2}{*}{2} & Errors & 5.3 & 6.2 & $8.5^{*}$ & $8.9^{*}$ & 7.4 & $8.3^{*}$ & $7.5^{*}$ & 7.6 & $7.9 *$ & $9.0 \dagger$ & $8.0^{*}$ & 6.9 \\
\hline & Time & 4.0 & 4.5 & 4.8 & 3.8 & 2.6 & $22.9 \dagger$ & 3.7 & 3.0 & $2.6^{*}$ & 5.8 & 4.7 & $2.0^{*}$ \\
\hline \multirow[t]{2}{*}{3} & Errors & 3.0 & 3.9 & 5.2 & $7.5^{*}$ & 5.9 & $6.9^{*}$ & $7.3^{*}$ & $5.9^{*}$ & 5.1 & 5.7 & $5.4^{*}$ & 4.7 \\
\hline & Time & 2.3 & 3.1 & 2.4 & 3.0 & 1.9 & $13.4 \dagger$ & 4.0 & 2.1 & 2.6 & 2.3 & $6.4^{*}$ & 1.7 \\
\hline \multirow[t]{2}{*}{4} & Errors & 5.3 & $1.7^{*}$ & $8.4^{*}$ & 7.7 & 6.3 & 7.3 & 4.7 & 7.0 & 7.4 & 8.8 & 7.6 & 4.2 \\
\hline & Time & 4.4 & 4.3 & 2.5 & 5.9 & 3.6 & $16.6 \dagger$ & 7.5 & 3.7 & $1.8 *$ & 2.7 & $7.4^{*}$ & $1.6^{*}$ \\
\hline \multirow[t]{2}{*}{5} & Errors & 5.5 & 5.9 & 5.5 & 7.1 & 7.4 & 7.4 & 7.2 & $7.8^{*}$ & $7.6^{*}$ & 8.8* & 6.2 & 4.1 \\
\hline & Time & 2.6 & 4.0 & 2.5 & 3.4 & 2.6 & $12.1 \dagger$ & 3.6 & 2.3 & 1.7 & 2.7 & $4.9 *$ & $1.2^{*}$ \\
\hline \multirow[t]{2}{*}{6} & Errors & 6.3 & 5.3 & 6.0 & $9.3^{*}$ & $8.7^{*}$ & 8.9 & $8.8^{*}$ & 8.1 & 8.1 & 9.3 & 7.0 & 5.5 \\
\hline & Time & 2.8 & 2.9 & 2.4 & 2.6 & 2.9 & $9.3 *$ & 3.4 & 2.9 & 1.7 & 2.7 & 3.5 & $1.0 *$ \\
\hline \multirow[t]{2}{*}{7} & Errors & 5.9 & 6.8 & 8.5 & $9.6 \dagger$ & 8.7 & 6.7 & $9.8 \dagger$ & 8.9 & 8.7 & 9.7 & $9.2^{*}$ & 4.2 \\
\hline & Time & 3.4 & 4.3 & 2.4 & 2.6 & 3.1 & $13.4 \dagger$ & 3.4 & 2.4 & $1.3 *$ & 2.2 & 4.4 & $1.1^{*}$ \\
\hline \multirow[t]{2}{*}{8} & Errors & 2.8 & 4.1 & 2.5 & $6.5 \dagger$ & $6.0^{*}$ & $6.8^{*}$ & $8.5^{*}$ & $7.1^{*}$ & 4.7 & $8.0^{*}$ & 3.4 & $6.0 *$ \\
\hline & Time & 2.2 & 3.8 & 1.8 & 2.1 & 2.6 & $8.7^{*}$ & 3.2 & 2.1 & 1.7 & 2.3 & 2.0 & $1.0^{*}$ \\
\hline \multirow[t]{2}{*}{ Total } & Errors & 40.1 & 41.4 & $54.5^{*}$ & $65.4 \dagger$ & $58.7 \dagger$ & $59.1 \dagger$ & $62.3 \dagger$ & $60.5 \dagger$ & $56.5 \dagger$ & $68.1 \dagger$ & $55.5 \dagger$ & 41.7 \\
\hline & Time & 27.0 & 32.9 & 22.7 & 30.4 & 23.0 & $122.4 \dagger$ & 33.9 & 23.7 & $15.8 \dagger$ & 25.7 & 40.0 & $12.4 \dagger$ \\
\hline
\end{tabular}

Note-Numbers in parentheses refer to group size. ${ }^{*}$ Differed from controls at least at .05 level. $†$ Differed from controls at least at .01 level.

motor- (or general) learning impairment, except possibly for the group with nigral damage.

The only recognizable clue as to the nature of the broad learning impairment (as well as the more narrow motorlearning impairment) emerges from the fact that virtually all components of the GLS are associated with the extrapyramidal motor system and, more specifically, with the basal ganglia and related structures. This would suggest that some disturbance in central mechanisms mediating bodily movement is the cause of deficient learning in our rats with lesions to the GLS. The character of this disturbance, however, remains elusive. While elementary motor disturbances affecting locomotion, posture, or muscle tone could explain acquisition deficits on timed tasks (puzzle-box problems), they could hardly account for acquisition deficits on untimed tasks (maze or visual discrimination problems) that simply require the subject to move from one locus within the environment to another to obtain a reward. Thus, a disturbance of a more complex motor (sensorimotor) function arising from basal gangliar injuries must lie at the basis of the generalized learning impairment. Some possibilities derived from certain theories about the function of the basal ganglia include a disturbance in response and cognitive sets Buchwald, Hull, Levine, \& Villablanca, 1975), executive functions (Stern \& Mayeux, 1986), motor planning (Marsden, 1982), fundamental (arousal, activation, attention, sequencing, motivation, and mood) functions (Cummings, 1986), or gating sensory information into other motor systems (Lidsky, Manetto, \& Schneider, 1985). Identifying the precise disturbance (or set of disturbances) underlying the generalized learning impairment could greatly increase our understanding about the psychology of learning and the corresponding neurobiological basis of behavioral plasticity.

\section{A Brain-Injured Animal Model of Mental Retardation}

As pointed out elsewhere (Archer, 1987; Thompson, Huestis, et al., 1986), the robustness of an animal model of mental retardation depends, at least in part, on the extent to which the experimentally treated animal exhibits learning deficits across a wide variety of laboratory tasks. In the case of our young rats treated with lesions to the GLS, this criterion would appear to be amply fulfilled. These rats have been reported to be deficient in learning detour problems, a 3-cul maze, visual and nonvisual discrimination habits (Thompson, Huestis, et al., 1986, 1987), and, as shown in the current study, motor-skill tasks. It is important to note that human retardates have been known for decades to exhibit learning deficits on discrimination, maze, detour (reasoning), and motor-skill tasks (Clarke \& Clarke, 1973; Denny, 1964; Miller et al., 1968; Zeaman \& House, 1967). Given this degree of concordance within the domain of learning, the GLS-lesioned rat would appear to have the potential to serve as a useful experimental model of certain classes of mental retardation. One of the more pressing problems for study would be to determine the cognitive nature of the generalized learning impairment, particularly concentrating on the issue of whether it is an expression of an aggregate of specific cognitive defects or the consequence of a unitary (general) defect (see Detterman, 1987).

From a neuropathological perspective, however, the usefulness of this model of mentally retarded rats is problematic for a number of reasons, not the least of which concerns the fact that mental retardation in humans is not usually associated with focal brain damage (Crome, 1960; Malamud, 1964). Nevertheless, our findings, which highlight the role of the basal ganglia and related structures in overall learning ability, may bear some relevance to 
the neuroanatomy of human mental retardation. For example, pathology of the basal ganglia is not uncommon in the mentally retarded (Crome, 1960; Malamud, 1964; Mito, Tanaka, Becker, Takashima, \& Junichi, 1986; Miyoshi, Matsuoka, \& Mizushima, 1969; Takashima \& Becker, 1985; Towbin, 1969). Furthermore, pathology of the basal ganglia and related nuclei in adult humans has been shown to be a consistent feature of "subcortical dementia" (Albert, 1978; Benson, 1983; Cummings, 1986; Huber \& Paulson, 1985), a clinical condition most recently described as consisting of "slowing of cognition, memory disturbances, difficulty with complex intellectual tasks such as strategy generation and problem solving, visuospatial abnormalities, and disturbances in mood and affect" (Cummings, 1986, p. 682). Since language functions are usually intact, this condition cannot be characterized as a general intellectual impairment, and, consequently, whatever similarities exist between subcortical dementia in humans and a generalized learning impairment in rats must be interpreted with caution. On the other hand, it is doubtful that humans with pathology to the basal ganglia or related nuclei suffer lesions of the same magnitude and bilateral symmetry as those with which our rats were prepared. It therefore remains possible that our findings on rats and those on humans with regard to the involvement of specific brain structures underlying the more serious manifestations of cognitive subnormality are not altogether unrelated.

\section{REFERENCES}

ACKerman, P. L. (1987). Individual differences in skill learning: An integration of psychometric and information processes perspectives. Psychological Bulletin, 102, 3-27.

AlberT, M. L. (1978). Subcortical dementia. In R. Katzman, R. D. Terry, \& K. L. Beck (Eds.), Alzheimer's disease: Senile dementia and related disorders (pp. 173-180). New York: Raven Press.

ARCHER, T. (1987). Towards animal models of mental retardation. Trends in Pharmacological Sciences, 8, 165.

Baumeister, A. A., Hawkins, W. F., \& Holland, J. (1966). Motor learning and knowledge of results. American Journal of Mental Deficiency, 70, 590-594.

Benson, D. F. (1983). Subcortical dementia: A clinical approach. $A d-$ vances in Neurology, 38, 185-194.

Berlucchi, G., Sprague, J. M., Levy, J., \& DiBerardino, A. C. (1972). Pretectum and superior colliculus in visually guided behavior and in flux and form discrimination in the cat. Journal of Comparative \& Physiological Psychology Monograph, 78, 123-172.

Buchwald, N. A., Hull, C. D., Levine, M. S., \& Villablanca, J. (1975). The basal ganglia and the regulation of response and cognitive sets. In M. A. B. Brazier (Ed.), Growth and development of the brain (pp. 171-189). New York: Raven Press.

Clarke, A. M., \& Clarke, A. D. B. (1973). Mental subnormality. In H. J. Eysenck (Ed.), Handbook of abnormal psychology (pp. 212258). San Diego, CA: Robert R. Knapp.

Crome, L. (1960). The brain and mental retardation. British Medical Journal, 1, 897-904.

Cummings, J. L. (1986). Subcortical dementia. British Journal of Psychiatry, 149, 682-697.

DENNY, M. R. (1964). Research in learning and performance. In H. A Stevens \& R. Heber (Eds.), Mental retardation (pp. 100-142). Chicago: University of Chicago Press.

DETTERMAN, D. K. (1987). Theoretical notions of intelligence and mental retardation. American Journal of Mental Deficiency, 92, 2-11.
Gentile, A. M., Green, S., Nieburgs, A., Schmelzer, W., \& Stein, D. G. (1978). Disruption and recovery of locomotor and manipulatory behavior following cortical lesions in rats. Behavioral Biology, 22, 417-455.

Heimer, L., Alheid, G. F., \& Zaborsky, L. (1985). Basal ganglia. In G. Paxinos (Ed.), The rat nervous system: Vol. 1. Forebrain and midbrain (pp. 37-86). New York: Academic Press.

Huber, S. J., \& PAulson, G. W. (1985). The concept of subcortical dementia. American Journal of Psychiatry, 142, 1312-1317.

KAHN, H., \& BURDETT, A. D. (1967). Interaction of practice and rewards on motor performance of adolescent mental retardates. American Journal of Mental Deficiency, 72, 422-427.

KolB, B., \& Holmes, C. (1983). Neonatal motor cortex lesions in the rat: Absence of sparing of motor behaviors and impaired spatial learning concurrent with abnormal cerebral morphogenesis. Behavioral Neuroscience, 97, 697-709.

KolB, B., \& WALKEY, J. (1987). Behavioral and anatomical studies of the posterior parietal cortex in the rat. Behavioral Brain Research, $23,127-145$.

KolB, B., Whishaw, I. O. (1983). Dissociation of the contributions of the prefrontal, motor, and parietal cortex to the control of movement in the rat: An experimental review. Canadian Journal of Psychology, 37, 211-232.

LASHLEY, K. S. (1929). Brain mechanisms and intelligence. Chicago: University of Chicago Press.

LASHLEY, K. S. (1935). Studies of cerebral function in learning: XI. The behavior of the rat in latch box situations. Comparative Psychological Monographs, 11, 1-42.

LidSKy, T. I., Manetto, C., \& SCHneider, J. S. (1985). A consideration of sensory factors involved in motor functions of the basal ganglia. Brain Research Reviews, 9, 133-146.

Malamud, N. (1964). Neuropathology. In H. A. Stevens \& R. Heber (Eds.), Mental retardation (pp. 429-452). Chicago: University of Chicago Press.

Marsden, C. D. (1982). The mysterious motor function of the basal ganglia: The Robert Wartenberg Lecture. Neurology, 32, 514-539.

Miller, L. K., Hale, G. A., \& Stevenson, H. W. (1968). Learning and problem solving by retarded and normal Ss. American Jourmal of Mental Deficiency, 72, 681-690.

Mito, T., Tanaka, T., Becker, L. E., Takashima, S., \& Junichi, T. (1986). Infantile bilateral striatal necrosis. Archives of Neurology, 43, 677-680.

Miyoshi, K., Marsuoka, T., \& Mizushima, S. (1969). Familial holotopistic striatal necrosis. Acta Neuropathologica, 13, 240-249.

Simenson, R. J. (1973). Acquisition and retention of a motor skill by normal and retarded students. Perceptual \& Motor Skills, 36, 791-799.

SPILIOTIS, P. H., \& THOMPSON, R. (1973). The "manipulative response memory system" in the white rat. Physiological Psychology, 1, 101-114.

Stern, Y., \& MayeuX, R. (1986). Intellectual impairment in Parkinson's disease. Advances in Neurology, 45, 405-408.

TAKASHIMA, S., \& BECKER, L. E. (1985). Basal ganglia calcification in Down's syndrome. Journal of Neurology, Neurosurgery, \& Psychiatry, 48, 61-64.

Thompson, R., Gallardo, K., \& Yu, J. (1984a). Cortical mechanisms underlying acquisition of latch-box problems in the white rat. Physiology \& Behavior, 32, 809-817.

Thompson, R., Gallardo, K., \&u, J. (1984b). Thalamic mechanisms underlying acquisition of latch-box problems in the white rat. Acta Neurobiologiae Experimentalis, 44, 105-120.

Thompson, R., Gates, C. E., \& Gross, S. A. (1979). Thalamic regions critical for retention of skilled movements in the rat. Physiological Psychology, 7, 7-21.

Thompson, R., Gibbs, R. B., Ristic, G. A., Cotman, C. W., \& Yu, J. (1986). Learning deficits in rats with early neurotoxic lesions to the globus pallidus, substantia nigra, median raphe, or pontine reticular formation. Physiology \& Behavior, 37, 141-151.

Thompson, R., Huestis, P. W., Crinella, F. M., \& Yu, J. (1986). The neuroanatomy of mental retardation in the white rat. Neuroscience \& Biobehavioral Reviews, 10, 317-338.

Thompson, R., Huestis, P. W., Crinella, F. M., Yu, J. (1987). 
Further lesion studies on the neuroanatomy of mental retardation in the white rat. Neuroscience \& Biobehavioral Revien's, 11, 415-440.

Thompson, R., Huestis, P. W., \& YU, J. (1987). Motor learning: Nonspecific subcortical mechanisms in rats. Archives of Physical Medicine \& Rehabilitation, 68, 419-422.

THOMPSON, R., \& YU, J. (1987). The neuroanatomy of learning and memory in the rat. In N. M. Milgram, C. M. MacLeod, \& T. L. Petit (Eds.), Neuroplasticity, learning, and memory (pp. 231-264). New York: Alan R. Liss.
Towbin, A. (1969). Mental retardation due to germinal matrix infarction. Science, 164, 156-161.

ZEAMAN, D., \& HousE, B. J. (1967). The relation of $1 Q$ and learning. In R. M. Gagne (Ed.), Learning and individual differences (pp. 192217). Columbus, OH: Charles E. Merrill.

Zilles, K. (1985). The cortex of the rat. New York: Springer-Verlag.

(Manuscript received February 19, 1988; revision accepted for publication July $8,1988$. ) 